\title{
AÇÕES DE SUSTENTABILIDADE DO DESCARTE E UTILIZAÇÃO DE CONCHAS DE MARISCOS NA COMUNIDADE PESQUEIRA DO DISTRITO DE LIVRAMENTO, SANTA RITA (PB)
}

Kleiton Luiz Sousa Pereira ${ }^{1}$

Alan Gurgel Saraiva ${ }^{2}$

Resumo: $O$ presente trabalho é uma pesquisa do Programa de Bolsas de Extensão (PROBEX) da Universidade federal da Paraíba (UFPB) realizada no ano de 2015 na comunidade de Livramento, no município de Santa Rita, estado da Paraíba. O trabalho teve como objetivo principal a realização de ações de Educação Ambiental com catadores de mariscos visando diminuir os impactos ambientais decorrentes do descarte das conchas. Os resultados obtidos mostram que a disposição inadequada das conchas dos mariscos traz sérios problemas ambientais. Mesmo com esta evidência, os marisqueiros, de uma maneira geral, não acreditam que estejam prejudicando o meio ambiente local.

Palavras-chave: Catadores de Marisco; Ações; Impactos Ambientais; Educação Ambiental. 


\section{Introdução}

No estado da Paraíba existem diversas comunidades pesqueiras que se encontram localizadas em vários municípios do litoral paraibano. Nestas comunidades, diversos recursos pesqueiros são capturados, dentre os quais várias espécies de peixes, moluscos e crustáceos, garantindo a estas tradicionais populações o sustento de suas famílias. Em muitas comunidades pesqueiras ao longo do litoral brasileiro, a captura do molusco Anomalocardia brasiliana, tem importância socioeconômica por ser utilizada como fonte de renda e também por ser fonte de alimentação familiar (Boehs et al.,2008). A espécie Anomalocardia brasiliana pode ser encontrada em ambientes que a salinidade varia entre 10 e 49 \%o (RODRIGUES et al.,2010).

Apesar da intensa captura que ocorre com os mariscos ao longo de boa parte do litoral da Paraíba, este recurso ainda se encontra com sua população em equilíbrio, o que garante que este recurso para as futuras gerações. A Carnicultura é uma atividade de grande valor econômico em regiões tropicais (PÁEZ-OSUNA, 2001a). Entretanto, esta atividade causa impactos ambientais e sociais devido ao descarte inadequado dos resíduos no solo. Lima e Lopes (2016) afirmam que o descarte inadequado de resíduos da captura do molusco $A$. brasiliana é um problema comum. Este problema além de causar a poluição do solo traz problema social para os pescadores que perdem parte de sua renda e da alimentação familiar com os moluscos que se tornam impróprios para consumo. Além disso, os pescadores artesanais enfrentam problemas comuns como a falta de equipamentos adequados para 0 trabalho, de infraestrutura para o beneficiamento e armazenamento do pescado, além da falta de unidades de comercialização (FIGUEIREDO; PROST, 2014).

$\mathrm{Na}$ comunidade pesqueira do Distrito de Livramento, município de Santa Rita, estado da Paraíba, a captura do marisco surge como uma das principais fontes de renda para diversas famílias, contudo, semelhantemente ao que ocorre em outras comunidades pesqueiras do estado, em Livramento a disposição destas conchas também é um problema ambiental e de saúde.

Sabendo que um dos objetivos da Educação Ambiental é adquirir uma consciência e sensibilidade para o meio ambiente e seus problemas (KONER,2017). O objetivo principal deste estudo foi diminuir o impacto da disposição das conchas de marisco (molusco Anomalocardia brasiliana) no manguezal por meio da Educação Ambiental, buscando-se com este projeto um método de descarte mais adequado para estas conchas e, ao mesmo tempo, utilizá-las em outras atividades como forma de complementar a renda dos catadores.

Os objetivos específicos são levantar contingente de catadores e catadoras de mariscos do Distrito de Livramento e os locais onde ocorrem os descartes das cochas destes moluscos, mobilizar os catadores e catadoras de mariscos da comunidade, a fim de levantar seus conhecimentos sobre os impactos ambientais decorrentes do descarte das conchas de mariscos e realizar oficinas de Educação Ambiental com estes catadores e catadoras,

Revbea, V. 14, № 2: 189-200, 2019. 
buscando formas de usar estas conchas como fonte complementar de renda familiar.

\section{Material e métodos}

Este trabalho foi realizado no período de maio a dezembro de 2015 na supracitada comunidade pesqueira do Distrito de Livramento (entre as latitudes $7^{\circ} 02^{\prime \prime} 35^{\prime \prime} \mathrm{S} ; 7^{\circ} 03^{\prime \prime 2} 24^{\prime \prime} \mathrm{S}$ e as longitudes $\left.34^{\circ} 54^{\prime \prime} 35^{\prime \prime} \mathrm{O} ; 34^{\circ} 53^{\prime \prime} 40^{\prime \prime} \mathrm{O}\right)$. Segundo D'Angelis (2014), o censo populacional do IBGE de 2010 afirma que o distrito de livramento possui 3616 habitantes, dos quais 2064 residem na comunidade.

Inicialmente a equipe do projeto se reuniu para discutir e alinhar toda a estratégica metodológica que deveria ser aplicada neste projeto. Posteriormente foi realizado o levantamento do material bibliográfico necessário, tanto na internet quanto na biblioteca central da UFPB. Uma vez tendo sido concluída estas primeiras etapas, a equipe passou a fazer os trabalhos de campo, os quais consistiram em realizar o reconhecimento da área de estudo, levantar o contingente de catadores e catadores de mariscos, mapeamento dos possíveis locais onde as conchas de mariscos são depositadas, levantar informações pertinentes a proposta do projeto diretamente com os catadores e, por fim, realizar na comunidade uma oficina de qualificação voltada para o artesanato, utilizando, como matéria-prima, as conchas de marisco.

Antes de iniciar os trabalhos relacionados com a atividade dos catadores de mariscos, toda a equipe, com exceção dos colaboradores externos, se dirigiu a comunidade pesqueira do Distrito de Livramento para conhecer os ambientes que eles utilizam no seu dia a dia no trabalho de catação e processamento, bem como os locais onde a maioria dos catadores reside. Para isso, a equipe inicialmente se reuniu com o presidente da Associação dos Moradores do Distrito de Livramento onde foi passado para ele, em detalhes, a proposta de trabalho com este projeto de pesquisa e, ao mesmo tempo, solicitando o seu apoio no sentido de acompanhar a equipe durante o trabalho preliminar de reconhecimento (Figura 1).

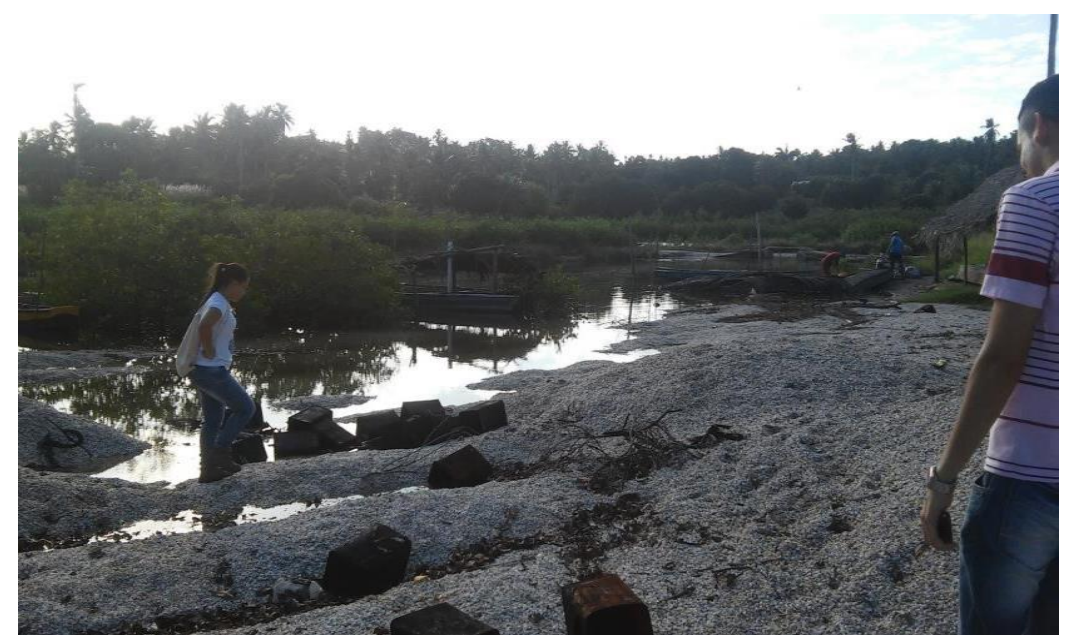

Figura 1: Equipe realizando trabalho de reconhecimento de área.

Revbea, São Paulo, V. 14, № 2: 189-200, 2019.

revista brasileira

educação ambiental 
O diálogo com a comunidade que está participando do estudo é fundamental para que o processo de uma educação transformadora aconteça (SOUZA; LOGAREZZI, 2018). Neste sentido, Torres-Guevara et al. (2016) afirma que o diálogo com pescadores é importante antes de realizar qualquer estudo em uma comunidade de pescadores porque a conversa pode fornecer informações importantes para o complemento científico.

Após a apresentação, o presidente da associação conduziu a equipe para uma localidade, conhecida como "Porto", que fica localizada em área adjacente ao mangue na margem esquerda de uma gamboa, local este onde a maioria dos catadores, após a atividade de coleta de marisco, se encontram para cozinhar os mariscos recém coletados, debulhar, que é o processo de retirada da carne, e ensacar em embalagens plásticas de $1 \mathrm{Kg}$. Em seguida, conduziu a equipe para as residências de alguns catadores, onde a equipe foi apresentada, visando facilitar o trabalho de aproximação e relacionamento entre a equipe técnica do projeto e os catadores de mariscos.

\section{a) Quantificação e Perfil dos Catadores e Catadoras}

Uma vez tendo sido feito o trabalho inicial de reconhecimento e de aproximação com os catadores, a equipe retornou à comunidade para levantar o contingente de catadores e catadoras envolvidas na coleta de marisco. Para tal, foi feita uma visita ao "Porto" onde se encontravam vários pescadores, dentre eles alguns catadores de mariscos, onde por meio de conversas informais, foi sendo levantado o número aproximado de pessoas que vivem da catação dos mariscos na comunidade de Livramento e seu modo de vida. Em seguida, a equipe foi nas principais ruas onde moram vários catadores e, também, mediante conversas informais, foi sendo complementado com novas informações sobre o perfil e o contingente de catadores e catadoras de marisco nesta comunidade.

b) Percepção dos Catadores e Catadoras em Relação ao Descarte das Conchas

Como a equipe já conhecia os locais onde os catadores se reuniam e onde a maioria residia, a etapa seguinte do projeto teve início, o levantamento de sua percepção ambiental sobre a problemática do descarte das conchas de mariscos. Para este fim, foi aplicado um questionário elaborado pela equipe técnica, com os catadores e catadoras de marisco do Distrito de Livramento. O estudo de percepção é um meio para compreender os valores e conceitos da sociedade que é alvo do estudo (Oliveira e Corona, 2008). Estes questionários foram aplicados inicialmente com os catadores que se encontravam no "Porto" e, posteriormente, com os demais em suas próprias residências (Figuras 2 e 3 ). 
Durante o emprego destes questionários, a equipe aproveitava para explanar sobre o projeto e já consultava se gostaria ou não de participar de uma oficina para aprender a trabalhar com artesanato, tendo como matériaprima as próprias conchas de mariscos. Para Costa et al. (2011), as oficinas oferecem vantagens como a melhora da qualificação profissional e de saúde das pessoas que estão envolvidas na oficina.

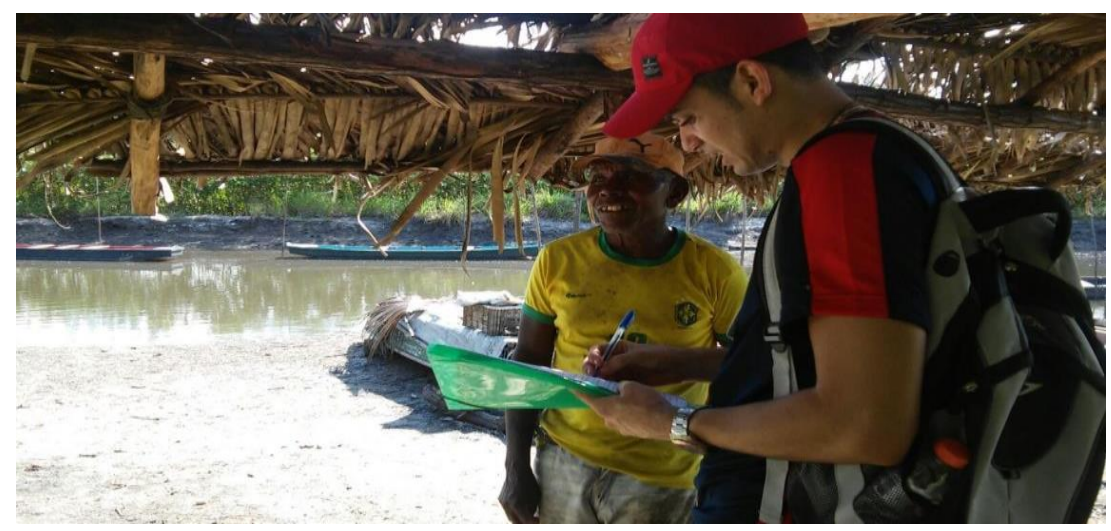

Figura 2: Membro da equipe entrevistando um marisqueiro no "Porto".

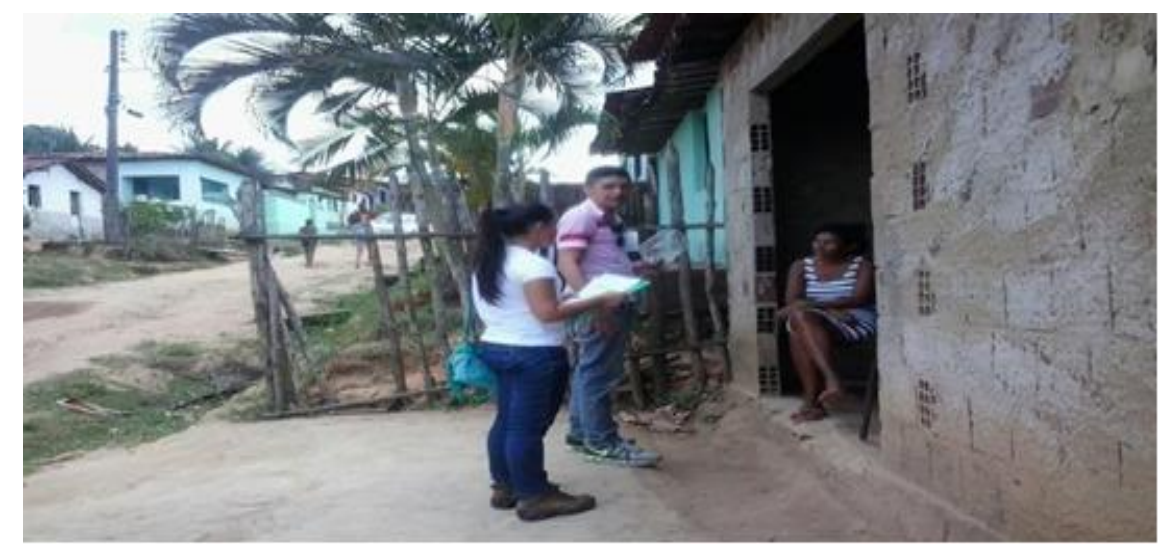

Figura 3: Equipe entrevistando uma marisqueira em sua residência.

\section{c) Levantamentos dos Impactos Ambientais}

Com base nas informações obtidas junto aos catadores e catadoras de mariscos, tanto através de conversas informais quanto através dos questionários, foi possível fazer um levantamento prévio dos locais onde havia disposição das conchas de mariscos. A partir de então, a equipe realizou visitas a estes pontos e outros adjacentes, onde foi realizado o levantamento visual dos eventuais impactos decorrentes do descarte das conchas, os quais eram anotados em planilha específica para este fim. Além disso, foram feitos registros fotográficos dos principais impactos. 


\section{d) Organizando da Oficina de Trabalho Artesanal}

Para a realização desta etapa do trabalho, a equipe técnica contou com o apoio da Federação da Agricultura e Pecuária do Estado da Paraíba FAEPA, a qual disponibilizou dois colaboradores para participarem deste projeto. A FAEPA se responsabilizou em contratar um instrutor com experiência, que neste caso teria que ser um artesão que confeccionasse peças artesanais a partir de conchas de mariscos, e disponibilizar todo o material necessário para a realização da Oficina de Trabalho Artesanal. Diante desta garantia, a equipe voltou à comunidade para relacionar os catadores e catadoras de marisco que estivessem interessados em realizar esta oficina, bem como encontrar, também, um ambiente na comunidade que fosse adequado para a realização da supracitada oficina.

As peças artesanais foram trabalhadas com temas relacionados à Educação Ambiental como não jogar lixo, a importância de fossas sépticas e sobre os problemas ambientais causados com o descarte incorreto das conchas dos mariscos sobre o rio e o manguezal.

Para Pereira (2008) trabalhar com pescadores artesanais usando a Educação Ambiental significa estar articulado com lutas sociais, com a expectativa da emergência de atores sociais, com a preservação e o reconhecimento de processos reversíveis e outros irreversíveis e com as relações econômicas de forma crítica. A Educação Ambiental tem um papel importante no pescador artesanal ao fortalecer o seu papel de cidadania e assim o torna um ator importante na transformação socioambiental (BRAIDO; CAPORLINGUA, 2014). Claro e Pereira (2017) destacam em seu estudo que a Educação Ambiental deve ser embasada em uma proposta dialógica, participativa e crítica.

\section{Resultados}

De acordo com o que foi levantado, através de observações visuais, de conversas informais com os catadores, da aplicação dos questionários e das eventuais informações voluntárias provenientes de moradores da região, mas que não são catadores de marisco, foi possível chegar aos seguintes resultados:

\section{a) Trabalho de Aproximação Junto aos Catadores}

Este contato inicial com os catadores e catadoras de marisco, mediado pelo presidente da Associação dos Moradores da Comunidade do Distrito de Livramento, foi de fundamental importância para a execução deste projeto, pois facilitou para que houvesse uma relação mais amistosa e de confiança entre os profissionais do ramo da catação de marisco e a equipe técnica do projeto (Figura 4). É importante ressaltar que sempre que se trabalha com a obtenção de dados oriundos de moradores de comunidades, é necessário que se haja esse tipo de aproximação inicial, a fim de garantir a confiabilidade dos dados levantados.

Revbea, V. 14, № 2: 189-200, 2019. 


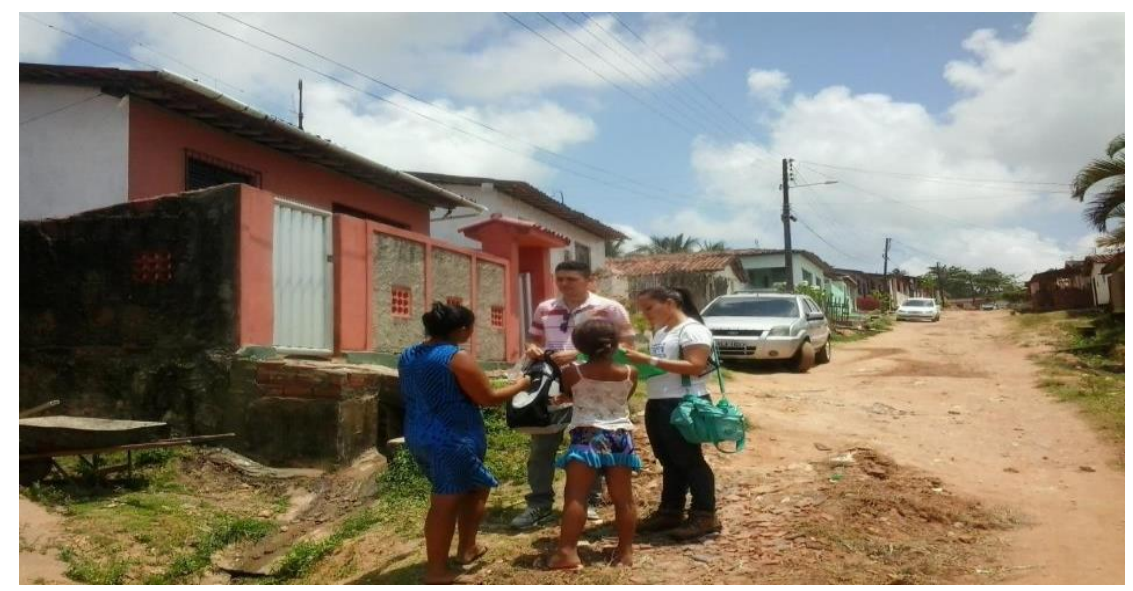

Figura 4: Conversa informal de aproximação entre a equipe e uma marisqueira.

\section{b) Quantificação e Perfil dos Catadores e Catadoras}

De acordo com as informações levantadas, há dezesseis pessoas que vivem da catação do marisco na comunidade. Deste total, onze foram entrevistados por meio da aplicação de questionários, sendo sete catadores e quatro catadoras.

Dentro deste pequeno universo amostral, o catador que está há menos tempo na atividade já tem experiência de quatro anos e o mais experiente vem praticando a mariscagem há vinte e cinco anos. Neste tipo de atividade, o aprendizado, em sua maioria, vem do convívio familiar, onde pais ou avós disseminam o seu conhecimento. É importante ressaltar que em alguns casos, os catadores antes de trabalhar na coleta de marisco atuavam em outras atividades pesqueiras e que só passaram a ser marisqueiros por conta da diminuição dos recursos pesqueiros que eles capturavam anteriormente, notadamente, peixe e camarão. Dessa forma, a mariscagem surge para certos pescadores como uma das poucas alternativas de sobrevivência e sustento familiar. A atividade de catação ocorre praticamente o ano todo, embora por ocasião das marés mortas e em épocas chuvosas, haja uma expressiva redução de captura.

É durante o período da maré baixa, quando os bancos ficam totalmente expostos, vai depender da altura da maré, que os catadores realizam suas atividades de coleta. Neste sentido, se deslocam para estes bancos quando a maré ainda está alta, mas começando a baixar, através de embarcações a motor ou a remo, usando uma gamboa que liga o "Porto" até o rio principal, o rio da Ribeira, na região que se encontra sob influência da maré. De uma maneira geral, costumam sair logo no início da manhã, por volta das 5:00h e retornam pela tarde, normalmente entre 14:00h e 16:00h, todavia, há registros de início de atividade na parte da tarde e encerramento no início da noite por volta das 20:00h. 


\section{c) Local de Descarte das Conchas de Mariscos}

Foi na citada região do "Porto" que, alguns anos atrás, vários marisqueiros se juntaram e construíram uma espécie de base (unidade de processamento) o marisco recém-coletado é cozinhado, a carne é removida, processo conhecido como debulhamento, e as conchas são descartadas na região lateral junto ao mangue, tornando está área como o principal ponto de descarte, onde se encontra um grande volume de conchas acumulado (Figura 5).

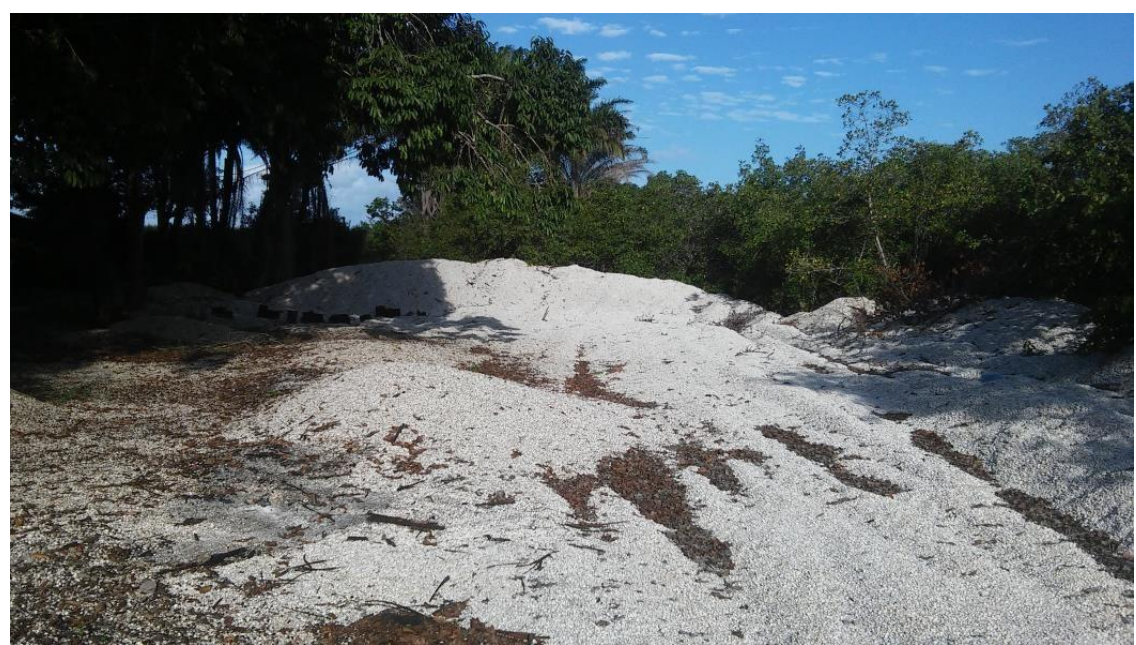

Figura 5: Principal ponto de descarte das conchas de mariscos, junto ao mangue no "Porto".

Além dessa área, a equipe identificou outros dois pontos de disposição, porém com um volume bem menor ao anterior (Figura 6). Entretanto a equipe acredita que deve haver outros pontos de descarte, tendo em vista que alguns marisqueiros terminam realizando todo o processo produtivo em casa e descartam as conchas em diferentes áreas da comunidade.

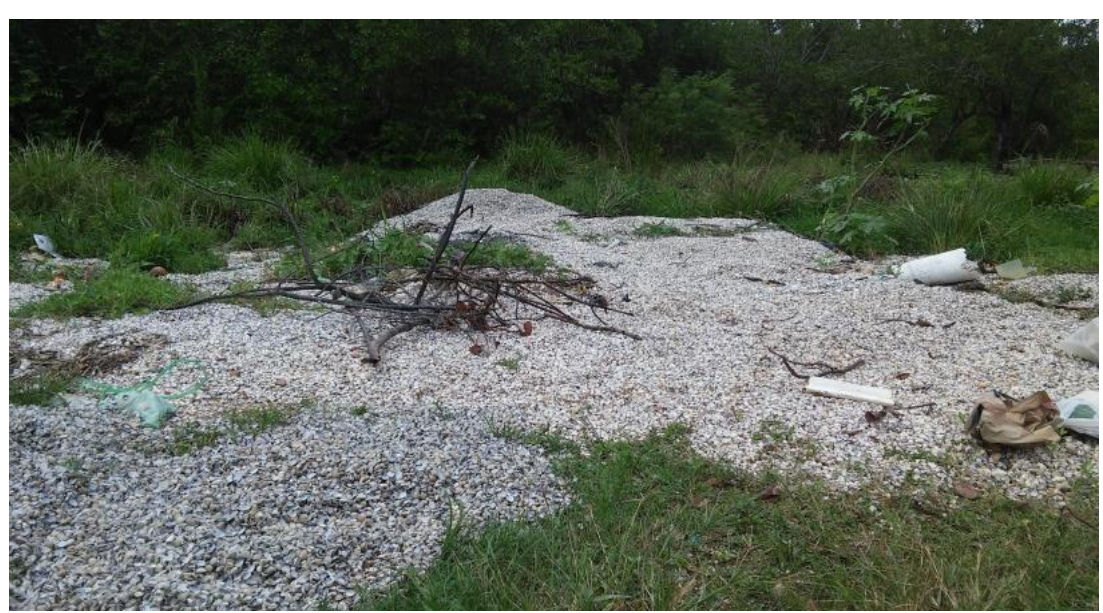

Figura 6: Local de pontos secundários de descartes das conchas de mariscos. 
d) Percepção ambiental dos Catadores e Catadoras em Relação ao Descarte das Conchas

De acordo com os questionários aplicados aos marisqueiros e as marisqueiras, somado as informações obtidas mediante conversas informais, ficou evidente que para estes profissionais da pesca, sua atividade não traz prejuízos nenhum para o ambiente, que no caso específico, o mangue e a região adjacente. Isto se deve ao baixo grau de escolaridade dos marisqueiros e marisqueiras. Este resultado está relacionado com o estudo de da Silva et al. (2017), neste estudo os autores relacionam o grau de percepção ambiental com o nível de escolaridade da pessoa, ou seja, quanto maior o nível de escolaridade da pessoa, maior é o nível de percepção ambiental. Alguns chegam até acreditar que jogar as conchas no mangue é benéfico, pois está devolvendo as conchas para o ambiente de onde foi retirado. Este fato mostra a falta de conhecimento ecológico por parte dos pescadores, conforme Ramenzoni (2013), a falta de conhecimento ecológico dos pescadores do leste da Indonesia é determinante para a poluição marinha daquela região.

\section{e) Levantamentos dos Impactos Ambientais}

O principal impacto da atividade de catação de marisco é o descarte em áreas inadequadas. Além de sufocar o mangue, como mostrado anteriormente, as conchas vêm também assoreando lentamente as margens da gamboa, que dá acesso ao rio da Ribeira, impedindo que as plântulas se desenvolvam (Figura 7).

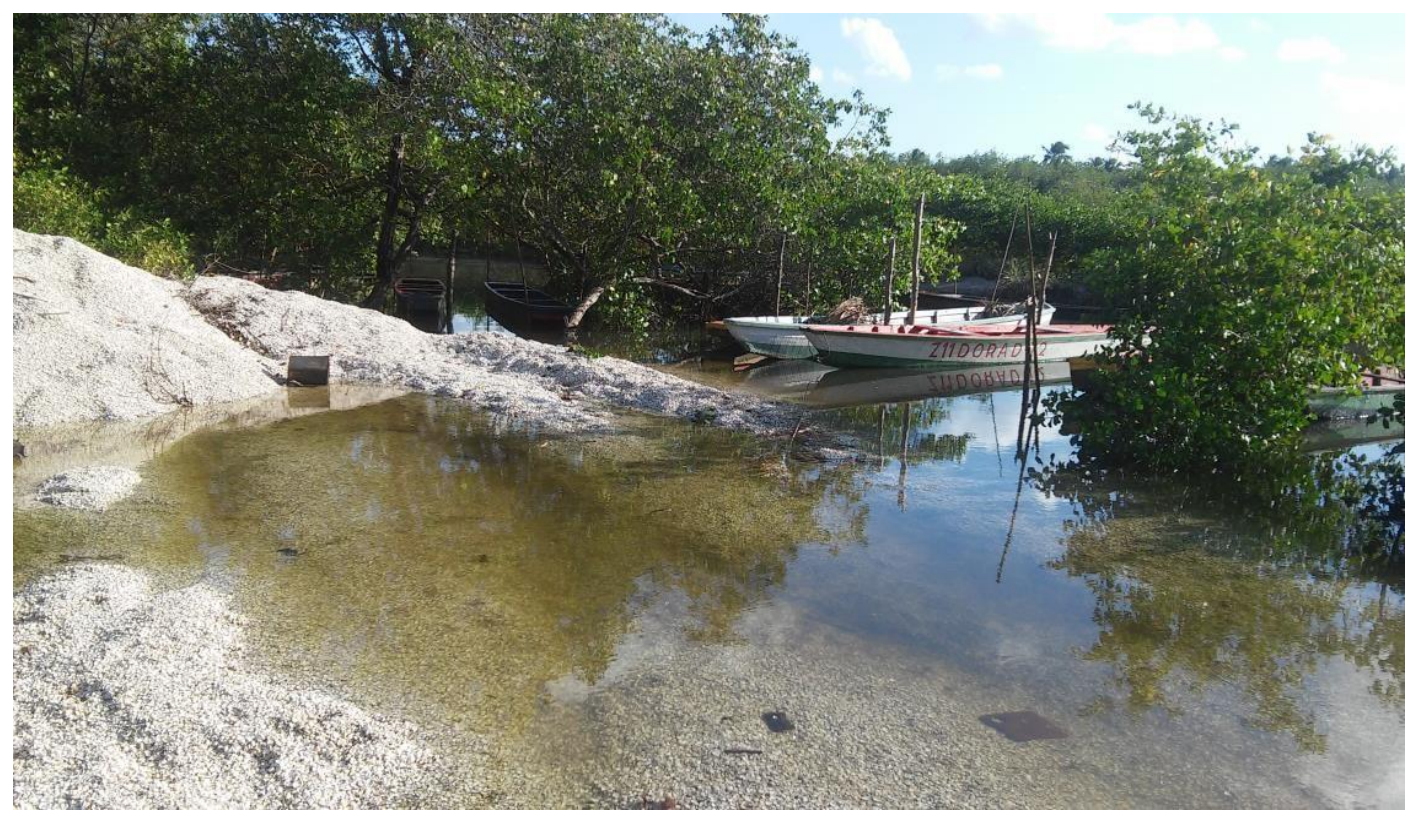

Figura 7: Conchas de marisco nas margens da gamboa. 
O amontoado de conchas que fica com restos de carne ainda preso, terminam por apodrecer provocando mau cheiro e atraindo vários animais indesejáveis, principalmente insetos, com destaque para as moscas do tipo varejeira. A intensificação desta atividade causará impactos negativos na qualidade da água por causa do aumento de nutrientes na água e alta turbidez devido as substâncias químicas (Thia Eng et al.,1989). Os efluentes são tipicamente enriquecidos em sólidos orgânicos suspensos, carbono, nitrogênio e fósforo (BIAO et al.,2004).

Além disso, foram verificados pequenos aglomerados de conchas, juntamente com outros resíduos sólidos, espalhados por outras áreas próximas ao mangue e, em alguns casos, até jogados nas ruas, incomodando a população local com o odor desagradável.

A sustentabilidade da carcinicultura depende de muitos fatores, como políticas e regulamentações completas, boa ecologia, excelente raça e tecnologia diversificada e tecnologia de garantia, bem como o apoio ao avanço tecnológico e a cooperação entre as indústrias (BIAO; KAIJIN, 2007). PáezOsuna (2001b) defende a ideia de que as fazendas de carcinicultura devem mudar de local caso estejam poluindo os corpos hídricos. O autor ainda acrescenta que os critérios para definição da área adequada devem ser refinados.

\section{f) Oficina de Trabalho Artesanal}

Durante as entrevistas os marisqueiros e familiares mostraram grande interesse de participar de oficinas sobre aproveitamento das conchas na confecção de produtos artesanais. Com isso foi formado uma turma composta por 20 alunos que participaram da oficina. O evento foi realizado com o apoio do presidente da Associação dos Moradores da Comunidade de Livramento, que cedeu um espaço numa escola municipal do Distrito de Livramento. A FAEPA disponibilizou um instrutor que ministrou o curso de confecção de peças de artesanato com utilização das conchas. $O$ curso teve uma carga horária de $32 \mathrm{~h}$ distribuídas em quatro sábados. O curso foi composto por palestras, treinamento prático de fabricação de peças e apresentação do produto no encerramento do curso.

O curso de trabalho artesanal foi proveitoso para comunidade, pois além do conhecimento sobre Educação Ambiental as famílias passaram a ter uma nova fonte de renda por meio do artesanato e contribuem minimizando os impactos por meio do descarte das conchas.

Evangelista-Barreto et al. (2014) afirmam que a aplicação da Educação Ambiental em comunidades pesqueiras é importante para fortalecer o engajamento e a conscientização dos pescadores de seu papel como agente de participação, controle e divulgação da proteção e manejo sustentável em seu habitat. 


\section{Conclusão}

Com os resultados obtidos, fica evidente que a disposição inadequada das conchas de mariscos traz sérios problemas ambientais como a poluição do mangue que fica na comunidade e poluição do solo em algumas áreas da comunidade. Mesmo com esta evidência, os marisqueiros, de uma maneira geral, não acreditam que estejam prejudicando o meio ambiente local, mas, apesar disso, estão dispostos a participarem de um curso de capacitação para minimizar eventuais impactos.

É importante que a UFPB e outras entidades da região realizem mais processos de Educação Ambiental para aumentar o grau de percepção e conscientização ambiental dos moradores do Distrito de Livramento. Uma vez, que os moradores da comunidade têm dificuldade de ter acesso a educação e a informação.

\section{Referências}

BIAO, X.; KAIJIN, Y. Shrimp farming in China: Operating characteristics, environmental impact and perspectives. Ocean \& Coastal Management, v. 50, n. 7, p. 538-550, 2007.

BIAO, X.; ZHUHONG, D.; XIAORONG, W. Impact of the intensive shrimp farming on the water quality of the adjacent coastal creeks from Eastern China.

Marine Pollution Bulletin,v. 48, n. 5-6,p. 543-553, 2004.

BOEHS, G.; ABSHER, T.M.; CRUZ-KALED, A.C. Ecologia populacional de Anomalocardia brasiliana (GMELIN, 1791) (Bivalvia, Veneridae) na Baía de Paranaguá, PR. Boletim do Instituto de Pesca, v. 34, n. 2, p. 259-270, 2008.

BRAIDO, J.A.; CAPORLINGUA, V.H. Da cidadania ambiental à Educação Ambiental política: desafios na pesca artesanal em Rio Grande - RS e São José do Norte - RS. Revista Direito Ambiental e sociedade, v. 4, n. 2, p. 179-205, 2014.

CLARO, L.C.; PEREIRA, V.A. Compreensões sobre a pretensa Educação Ambiental do Estado sob a crítica da ecologia política: as relações entre a EMATER e uma comunidade de pesca artesanal na década de 1990. Revbea, São Paulo, v. 11, n. 5, p. 89-100, 2017.

COSTA, M.C.A.; CORNELLO, D.M.; TETTE, R.P.G.; REZENDE, M.G.; NEPOMUCENO, M.F. Inclusão social pelo trabalho: a qualificação profissional para pessoas com deficiência intelectual. Gerais: Revista Interinstitucional de Psicologia, v.4, n.2, p. 200-214, 2011.

D'ANGELIS, I.A.B. o conhecimento ecológico local como ferramenta na gestão pesqueira participativa: um estudo de caso com os marisqueiros de Livramento, Santa Rita-PB. Dissertação (Programa de Pós-Graduação em Desenvolvimento e Meio Ambiente), Universidade Federal da Paraíba,João Pessoa, 2014. 
DA SILVA, M.L.A.; PAIVA, L.S.; ARAÚJO, M.F.V.; CONCEIÇÃO, G.M. Percepção ambiental dos moradores do Parque Nacional da Chapada das Mesas, no domínio fitogeográfico do Cerrado Brasileiro. Espacios, v. 38, n. 22, p. $33-50,2017$.

EVANGELISTA-BARRETO, N.S.; DALTRO, A.C.S.; SILVA, I.P. BERNARDES, F.S. Indicadores socioeconômicos e percepção ambiental de pescadores $\mathrm{Em}$ São Francisco do Conde, Bahia. Boletim do Instituto de Pesca,v. 40, n. 3,p. 459-470, 2014.

FIGUEIREDO, M.M.A.; PROST, C. O trabalho da mulher na cadeia produtiva da pesca artesanal.Revista Feminismos, v. 2, n.1, p. 82-93, 2014.

KONER, S. Need for and Importance of Environmental Education. International Journal of Current Research and Modern Education, v.2, n.2, p 198-199, 2017.

LIMA, G.F.; LOPES, R.L. Impactos ambientais dos resíduos gerados na pesca artesanal de moluscos bivalve no distrito de Patané/Arez-RN. HOLOS, Ano 32, v. 4, p. 206-216, 2016.

OLIVEIRA, K.A.; CORONA, H.M.P. A percepção ambiental como ferramenta de propostas educativas e de políticas ambientais. Revista Científica ANAP Brasil, v.1, n. 1, p. 53-72, 2008.

PÁEZ-OSUNA, F. The environmental impact of shrimp aquaculture: a global perspective. Environmental Pollution, v. 112, n. 2, p. 229-231, 2001a.

PÁEZ-OSUNA, F. The Environmental Impact of Shrimp Aquaculture: Causes, Effects, and Mitigating Alternatives. Environmental Management, v. 28, n. 1, p. 131-140, 2001b.

PEREIRA, M.O.R. Educação Ambiental Com pescadores Artesanais: um convite à participação. Revista Praxis Educativa, v. 3, n.1, p. 73-80, 2008.

RAMENZONI, V.C. Endenese fisheries: Exploratory findings on environmental perceptions, fish effort, and overfishing in Eastern Indonesia. Ethnobiology Letters, v.4, n.1, p. 39-51, 2013.

RODRIGUES, A.M.L; BORGES-AZEVEDO, C.M.; HENRY-SILVA, G.G. Aspectos da biologia e ecologia do molusco bivalve Anomalocardia brasiliana (Gmelin, 1791) (Bivalvia, Veneridae). Revista Brasileira de Biociências, v. 8, n. 4, p. 377-383,2010.

SOUZA, S.C.; LOGAREZZI, A.J.M. Educação Ambiental dialógico-crítica no Pantanal de Mato Grosso: a voz e o silêncio das pescadoras e dos pescadores tradicionais. Revbea, São Paulo, v. 13, n. 1, p. 322-343, 2018.

THIA ENG, C.; PAW, J.N.; GUARIN, F.Y. The environmental impact of aquaculture and the effects of pollution on coastal aquaculture development in Southeast Asia. Marine Pollution Bulletin, v.20, n.7, p. 335-343, 1989.

TORRES-GUEVARA, L.E.; LOPEZ, M.C.; SCHLÜTER, A. Understanding Artisanal Fishers' Behaviors: The Case of Ciénaga Grande de Santa Marta, Colombia. Sustainability, v. 8, n. 6, p. 549-565,2016. 